\title{
Analysis of the vegetation structure of a Sargassum community in the Philippines*
}

\author{
P. O. Ang, Jr.** \\ Marine Sciences Center, University of the Philippines, Diliman, Quezon City, Philippines
}

\begin{abstract}
A zonation study of Sargassum siliquosum J. Ag., S. paniculatum J. Ag. and other Sargassum spp. was conducted using line transects. The structure of the community was analyzed using Principal Component Analysis (PCA) and the relation between percentage cover of the different dominant species and environmental parameters was extracted using Canonical Correlation Analysis. Results show that variation in the community structure was primarily accounted for by the less dominant algae taken together. Individually, however, contributions of these algae were easily masked by the contribution from the most dominant Sargassum spp. Significant canonical correlation $(p<0.05$ ) was extracted between algal cover, primarily that of Sargassum, and temperature and tidal level. Significant correlation was also extracted between algal cover and the antecedent events of minimum temperature, mean lowest low tide levels and water movement.
\end{abstract}

\section{INTRODUCTION}

Extensive beds of Sargassum are common in rocky intertidal and shallow subtidal areas of the Philippines. Large quantities of this alga can often be found cast up on the shore or beaches after a heavy storm. Because of its potential as animal feed and as source of alginate, there has recently been an increased interest in this alga. Except for work by Saraya (1976) and Cordero $(1978,1980)$, very little information is available on the general biology and ecology of this plant in the Philippines.

This paper presents an initial attempt to describe the structure of a Sargassum community in terms of the zonation and percentage cover of the dominant Sargassum species and those of the associated macrobenthic algae. It is also an attempt to find out if there is a seasonal variation in this structure and whether this variation, if detected, can be correlated with, or explained by, variation in the environmental conditions.

The Sargassum community studied is located near Balibago, Calatagan, Batangas (13 $56^{\prime} \mathrm{N}, 120^{\circ} 37^{\prime} 24^{\prime \prime}$

\footnotetext{
- Contribution no. 118 from the Marine Sciences Center, University of the Philippines

- Present address: Department of Botany, University of British Columbia, Vancouver, B. C. V6T 2B1, Canada

E) (Fig. 1). It covers an area about $150 \mathrm{~m}$ wide and 300 to $400 \mathrm{~m}$ long. This area, following the contour of the reef flat in a north-southeast orientation, has a slope of less than $15^{\circ}$. It is bordered on the northwest and on the southeast by a $3 \mathrm{~m}$ drop in elevation. On the north and northeast fringes, the area becomes gradually covered with sand. The substratum is generally of small coral boulders, with sand patches in between.

\section{MATERIALS AND METHODS}

Zonation of Sargassum species. A $100 \mathrm{~m}$ calibrated transect line was placed across the Sargassum bed in a direction perpendicular to the shore. The zero point of the line coincided with the shoreward edge of the bed. A $1 \mathrm{~m}^{2}$ quadrat, made up of 2 halves free of any crossing bars, was placed at $5 \mathrm{~m}$ intervals starting from the $10 \mathrm{~m}$ mark of the line. All the Sargassum plants within the quadrat were identified, if possible, to the species level. A maximum of 15 quadrats was sampled monthly from June 1979 to June 1980. However, owing to difficulties in identifying young, immature or senile Sargassum plants, only samples from the months August to November 1979 are considered in this paper This is the period when the plants become fertile (Ang 1985), hence the distinctive morphologies of the reproductive structures were available for species identifi- 


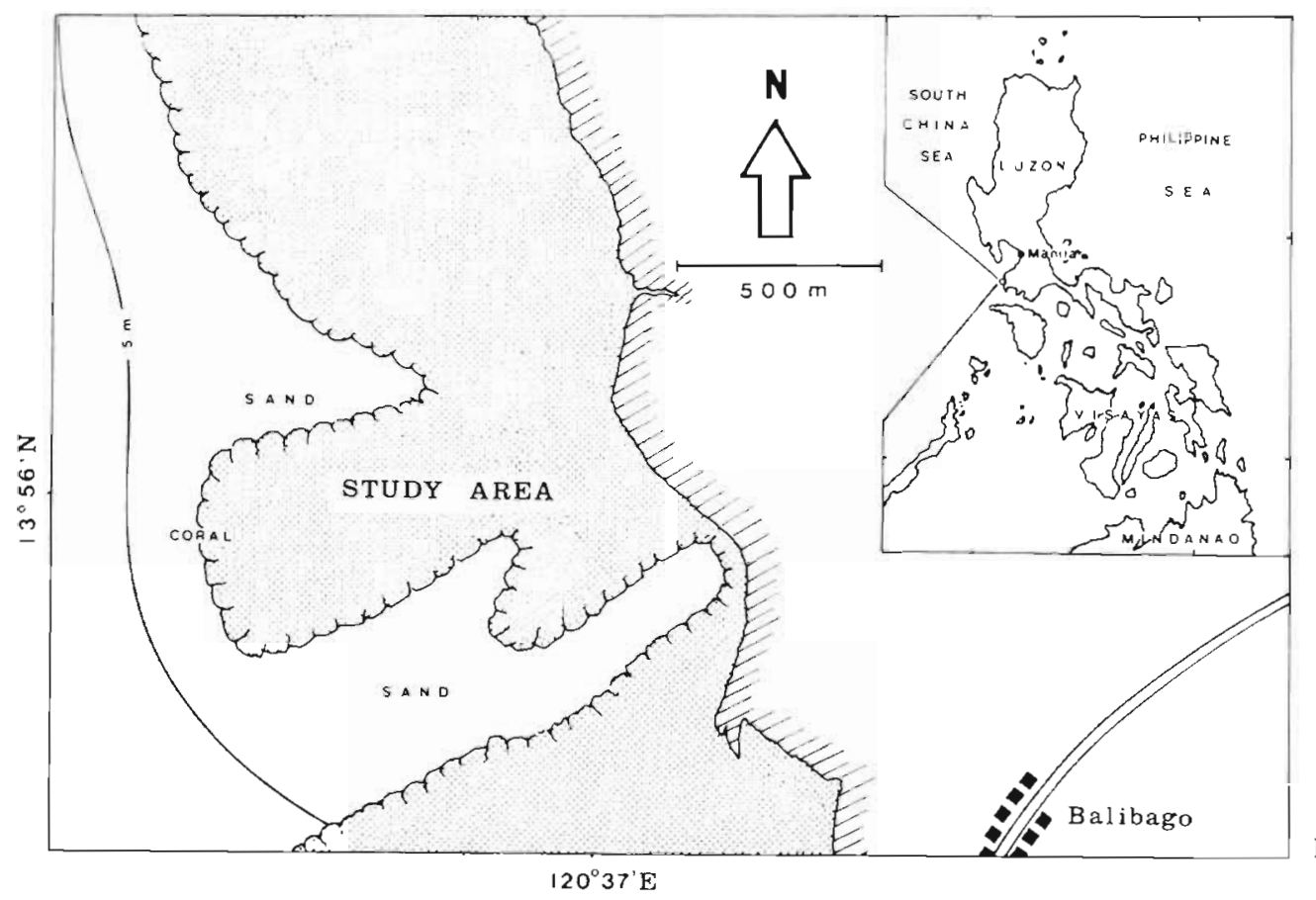

Fig. 1. Map of the study area

cation. Water visibility was extremely poor in September, so only 10 quadrats were sampled on September 29, 1979.

Frequency of occurrence and percentage algal cover. Systematic sampling was also employed to estimate the frequency of occurrence of the macrobenthic algae and their percentage cover At each sampling, a single transect line was placed perpendicular to the shore with the starting end corresponding to the shallow shoreward edge of the bed marked as the zero point. Different sizes of quadrat were tested and $1 / 4 \mathrm{~m}^{2}$ was found to be the minimum area that gave an approximately contant number of species. The $1 / 4 \mathrm{~m}^{2}$ quadrat was subdivided into 25 smaller squares and was placed on the transect line at every $5 \mathrm{~m}$ interval. Frequency of occurrence of each species per quadrat was quantified in percentage terms by dividing the number of smaller squares containing that species by 25, and multiplying by 100 (Saito \& Atobe 1970). Percentage values of all the quadrats in each transect were then averaged to give the mean frequency of occurrence. The percentage cover of each species per quadrat was computed in a simlar manner, by dividing the sum of all the percentage cover estımates of each of the smaller squares by 25 , and averaging the quadrat values per transect to obtain the mean percentage cover

Sampling was done every alternate month starting in June 1979, for a period of 1 yr. A total of 97 quadrats were sampled over the 7 sampling periods, distributed as follows: in 1979, 10 on June 29, 14 on August 24, 15 on October 27, 14 on December 2; in 1980, 14 on February 8, 15 on April 9, and 15 on June 28. In estimating both the frequency of occurrence and the percentage cover of the algae, all Sargassum plants were counted as 1 'species'. This was done because the lateral branches of neighboring Sargassum plants were often intertwined and pressed against each other under the quadrat and impossible to separate.

A short survey of the Sargassum bed indicated the presence of 3 levels of vertical vegetation structure, namely: the upper canopy layer consisting of the Sargassum plants; an understorey layer of other associated macrobenthic algae; and an encrusting layer consisted of the epilithic microalgae. Because the study of microalgae entails a different sampling methodology, this layer of vegetation was not included in the present analysis.

Environmental parameters. Environmental parameters, namely water movement, salinity, maximum, minımum, and mean temperatures, soluble reactive phosphorus, daylength, weekly mean lowest tide and mean tide level, were measured every 2 or $3 \mathrm{wk}$ over the 1 yr period. Water movement was measured using the clod card method (Doty 1971a), and was expressed as a Diffusion Index (Df). Surface water salinity was measured using an AO Temperature Compensated Refractometer. Maxımum and minimum temperatures were measured using a Taylor Max/Min Registering thermometer. Additional temperature readings were taken at different times of the day and the mean temperature was the average of all the readings within a $24 \mathrm{~h}$ perıod. Soluble reactive phosphorus was determined using the method of Strickland \& Parsons (1972). 
Daylength values were taken from the sunrise-sunset tables of the Philippine Bureau of Coast and Geodetic Survey (BCGS 1979, 1980) and extrapolated for $14^{\circ} \mathrm{N}$. Tide readings were based on the tide at Manila (BCGS 1979, 1980) and corrected for Calatagan, Batangas. Daily lowest tide readings were averaged every $7 \mathrm{~d}$ to give the weekly mean lowest tide level. Similarly, daily mean tide readings were averaged to give the weekly mean tide level.

Analysis. A Principal Component Analysis (PCA) was employed to describe the vegetation data. Canonical Correlation Analysis was used to extract the relation between the vegetation and environmental variables. The usefulness of Canonical Correlation Analysis in extracting ecological information of this sort has been assessed by Gittins (1979).

The percentage cover data were compiled as a data matrix with the species as variables and the quadrats as cases. Although the present set of data satisfies the requirements listed by Jeffers (1978) for PCA, the presence of an excessively dominant variable and correspondingly numerous zero values in the other variables reduces the effectiveness of this technique (Legendre \& Legendre 1983). To overcome this, all cases were normalized using $\log (\mathrm{x}+1)$ transformation to reduce the relative weights of the dominant variables with respect to those of the less dominant ones (Aart \& Smeenk-Enserik 1975, Legendre \& Legendre 1983). An initial PCA was then performed, and those species not significantly accounted for by the first 4 component axes of this analysis (i.e. which do not show significant correlation at $\mathrm{p}=0.01$ ) were combined to form 2 composite variables, namely, wet-month algae and dry-month algae. These algae were grouped respectively based on whether they appeared in the wet months (Jun to Oct) or in the dry months (Feb to Apr). In order to overcome the presence of numerous zeros due to the absence of many species at different times, cases were also combined. Since the transect line was laid perpendicular to the shore, samples from every 4 or 5 quadrats along the line were combined to form 3 composite data sets ( 2 sets for June 29,1979 ) corresponding roughly to a set closest to the shore (S), a set in the middle (M), and a set closest to the drop off (D). Reduction in the proportion of cases with zero value enhances the continuity of the data (Gittins 1979). Since only the less significant variables were combined, this resulted in no significant loss of information. A vegetation data matrix with 8 variables and 20 cases was thus used for further analysis.

Environmental data were compiled into 2 data matrices. In both, readings of the environmental parameters taken at different periods were taken as the cases and the different environmental parameters as variables. $\log (x+1)$ transformation was also performed to normalize all cases. The first matrix, termed the regular data matrix, was composed of cases measured contemporaneously with the vegetation data. The second matrix, termed the antecedent data matrix, was composed of cases measured 2 or $3 \mathrm{wk}$ ahead of the vegetation sampling period. Both matrices had 20 cases corresponding to those of the vegetation data matrix.

Two Canonical Correlation Analyses were performed. The first was between the first 2 PCA axes of the vegetation data matrix and the first 2 PCA axes of the regular environmental data matrix. The second analysis was between the same 2 vegetation PCA axes and those of the antecedent data matrix. The rationale of this second correlation analysis is based on the idea that a time lag may be experienced before the effect of any environmental change can be manifested in the organism. This concept was discussed by Doty (1971b).

All computations were done on a computer terminal (Model Ann Arbor Ambassador) under the Michigan Terminal System (M.T.S.) of the University of British Columbia computer system. Statistical analysis was based on the Michigan Interactive Data Analysis System (MIDAS) described by Fox \& Guire (1976), and on the work of Gittins (1979)

\section{RESULTS}

\section{Sargassum spp. composition and zonation}

Although there are 8 species of Sargassum reported from the area (Ang 1982), most of these were uncommon and were found only along the reef-flat edge. Fig. 2 shows the summarized picture of the zonation of the 2 dominant Sargassum species, S. siliquosum J. Ag. and S. paniculatum J. Ag., along the 4 transects laid from August to November 1979. This shows that the first 3 quadrats constituted a zone composed of more than $70 \% S$. siliquosum. At the other extreme, the last 3 quadrats constituted a zone of over $65 \% \quad S$. paniculatum. In the middle was a transition zone with $S$. siliquosum slightly more dominant up to the 9 th quadrat. The zonations at the extremes were consistent in all the transects, but in the transition zone, either one of the 2 species may be slightly more dominant than the other.

Sargassum siliquosum constituted $50.4 \%$ of the total number of whole Sargassum plants counted, and $S$. paniculatum, $47.7 \%$. The mean ratio of $S$. siliquosum to $S$. paniculatum was 1.1. Other species constituted only $2 \%$ of the total number of Sargassum plants examined. 


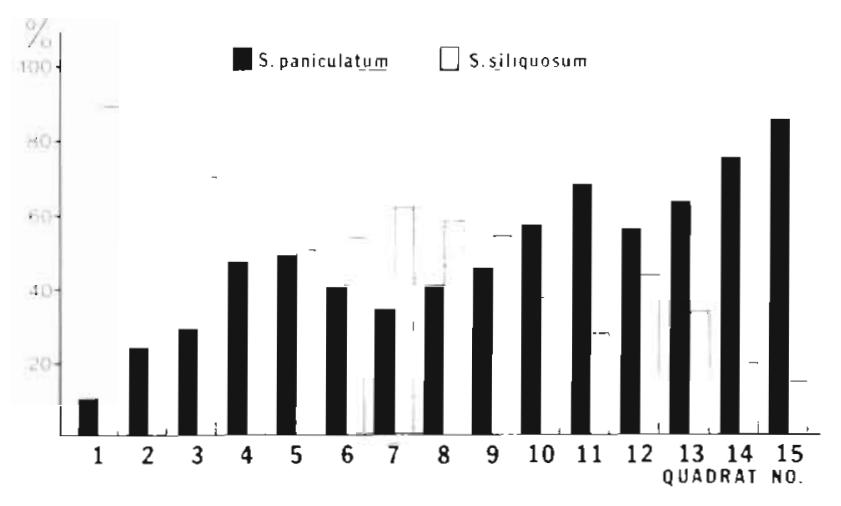

Fig. 2. Summary of percentage composition of Sargassum siliquosum and $S$ paniculatum in the quadrats of the 4 transects laid from Aug to Nov 1979

\section{Dominant algal species}

Apart from the several species of Sargassum, there were 30 other macrobenthic algal species found in the Sargassum bed. Their percentage frequencies of occurrence are summarized in Table 1 The greatest number of algae was observed in February and the least in August and October. Species such as Acetabularia dentata, Amphiroa fragilissima, Caulerpa sertularioides, Dictyota sp. and Halimeda opuntia occurred throughout or almost throughout the entire year. Other, such as several species of Caulerpa, Codium arabicum, Dictyosphaeria cavernosa and Hydroclathrus clathratus were seasonal and appeared during the drier months (Feb to Apr). Hormophysa triquetra, Udotea orientalis and Lobophora variegata were also seasonal, but they appeared during the wet months (Jun to Oct). December appeared to be more of a transition period when some of these wet-month algae (e.g. $H$. triquetra) and dry-month algae (e.g. $D$. cavernosa) could both be found. Gracilaria coronopifolia, G. eucheumoides, Valonia ventricosa and others were rare $(<1 \%)$ and appeared only occasionally in the samples.

Among the 31 species recorded, including the different species of Sargassum counted as one, 17 are

Table 1 Percentage frequencies of occurrence of macroalgae in the Sargassum bed

\begin{tabular}{|c|c|c|c|c|c|c|c|}
\hline Species & $\begin{array}{c}\text { Jun } 29 \\
1979\end{array}$ & $\begin{array}{c}\text { Aug } 24 \\
1979\end{array}$ & $\begin{array}{c}\text { Oct } 27 \\
1979\end{array}$ & $\begin{array}{c}\text { Dec 2 } \\
1979\end{array}$ & $\begin{array}{c}\text { Feb } 8 \\
1980\end{array}$ & $\begin{array}{c}\text { Apr 9, } \\
1980\end{array}$ & $\begin{array}{c}\text { Jun } 28 \\
1980\end{array}$ \\
\hline Acetabularia dentata Solms-Laubach & 2.0 & & & 0.9 & 4.6 & 0.8 & 1.1 \\
\hline Amphiroa foliacea Lamx. & & & & 0.3 & 0.6 & & \\
\hline A. fragilissima Lamx. & 4.8 & 9.1 & 7.7 & 8.6 & 8.9 & 13.1 & 11.5 \\
\hline Boergesenia forbesii (Harv.) Feldmann & & & & & 0.3 & & \\
\hline Caulerpa lentillifera J. Ag. & & & & & 0.3 & & 1.9 \\
\hline C. racemosa (Forsk.) J. Ag. & & & & & 1.1 & 0.5 & \\
\hline C. serrulata (Forsk.) J. Ag. & & & & & 0.6 & & \\
\hline C. sertularioides (Gmelin) Howe & 6.8 & & 0.3 & 4.0 & 0.6 & 8.5 & 12.5 \\
\hline Codium arabicum Kutz. & & & & & 2.3 & 0.5 & \\
\hline Dictyosphaeria cavernosa (Fors.) Boerg. & & & & 1.1 & 0.3 & & \\
\hline Dictyota sp. & 0.8 & & & 0.9 & 0.5 & 2.9 & 1.6 \\
\hline Galaxaura obtusata (Ell. et Sol.) Lamx. & & & & 0.3 & & & \\
\hline Gracilaria coronopifolia J. Ag. & & 0.3 & & 0.3 & & & \\
\hline G. eucheumoides Harv. & & 0.3 & & & & & \\
\hline Halicoryne wrightij Harv. & & & & 0.6 & & & \\
\hline Halimeda macroloba Asken. & 0.4 & & & & 0.3 & & 0.8 \\
\hline H. opuntia Lamx. & 2.8 & 1.3 & 0.5 & 2.3 & 0.9 & 1.3 & 8.3 \\
\hline H. tuna (Ell. et Sol.) Lamx. & & & & & & 0.5 & \\
\hline Hormophysa triquetra (L.) Kutz. & & 1.1 & 0.5 & 2.0 & & & 0.3 \\
\hline Hydroclathrus clathratus (Ag.) Howe & & & & & 0.6 & 1.3 & \\
\hline Jania capillacea Harv. & & & & & 0.3 & 1.1 & \\
\hline Laurencia sp. & & & & & & & 0.3 \\
\hline Liagora sp. & & & & & 0.9 & & \\
\hline Lobophora variegata (Lamx.) Womersley & 0.8 & 7.2 & 1.3 & 2.6 & & & \\
\hline Neomeris van-bossae Howe & & & & & 0.6 & & 0.3 \\
\hline Padina australis Hauck & 0.8 & & & 0.3 & 0.3 & 4.3 & 0.5 \\
\hline Sargassum spp. & 62.4 & 43.9 & 70.8 & 29.9 & 36.0 & 34.4 & 49.9 \\
\hline Udoted orientalis A \& E S Gepp & 1.2 & & 1.1 & & & & 1.9 \\
\hline Ulva reticulata Forsk. & & & & 0.9 & & & \\
\hline Valonia aegagropila J. Ag. & & & & & & & 0.3 \\
\hline V. ventricosa J. Ag. & & & & 0.3 & & & \\
\hline Total no. of species present & 10 & 7 & 7 & 16 & 19 & 10 & 13 \\
\hline
\end{tabular}


chlorophytes (green algae), 6 are phaeophytes (brown algae), and 8 are rhodophytes (red algae).

\section{Environmental parameters}

Water movement, temperature, and daily fluctuations in tidal levels are presented in Fig. 3 . There is a range of $12{ }^{\circ} \mathrm{C}$ between the maximum temperature of $36.5^{\circ} \mathrm{C}$ in November and the minimum temperature of $24.5^{\circ} \mathrm{C}$ in January. The maximum temperature was measured at daytime low tide, when water movement was minimal. A fluctuation pattern is less discernible with water movement. Apparently, the water became calmer towards April and May. Tides were generally higher in August to November and lowest tides were recorded in late December to February during daytime.

Among the other physical parameters (not shown), changes in salinity did not show any distinct seasonal pattern. Soluble reactive phosphorus was generally higher $(0.08$ to $0.12 \mathrm{ppm})$ in the wet months and lower $(0.05$ to $0.07 \mathrm{ppm})$ in the dry months. The time difference between the shortest day in December and longest day in June is only $2 \mathrm{~h}$.

\section{Community analysis}

Sargassum spp. clearly stand out as the most dominant organisms. Their average percentage cover in each sampling period, together with those of the next 5 most dominant species, are listed in Table 2. Many species were present only in very small amounts and were absent in many cases. Thus the characteristic of the data matrix is one in which a single species (Sargassum spp.) has very high cover values, and most of the other species have very low cover and are present only in a very few quadrats.

The results of PCA of the vegetation data (Table 3) show $95 \%$ of the variation within the community to be accounted for by the first 2 component axes. The first axis (PCA 1) is basically accounted for by the variation of all the other associated macroalgae except Sargassum. The second axis (PCA 2) describes the variation that is almost purely due to Sargassum spp., with a little contamination from Amphiroa fragilissima. The other PCA axes are less interpretable, and are therefore discarded from further analysis.

Scattering in the plot of PCA 2 against PCA 1 (Fig. 4) shows that the 20 cases of vegetation data can roughly be divided into 5 clusters. Cluster A is composed of cases with the highest percentage of Sargassum cover, Cluster B of cases with a relatively high cover of both Sargassum spp. and the other species. Cluster C corresponds to cases with a relatively high cover of Sargassum spp. but with very low cover of other species. Cluster D is composed of cases with higher cover of other species and low cover of Sargassum spp., whereas cases in Cluster $E$ have low overall algal cover.
Fig. 3. Fluctuation of environmental parameters. (A) Water movement (diffusion index). (B) Mean water temperature; vertical bars indicate the range from minimum to maximum temperatures. (C) Daily mean tide level (DMT) and daily lowest low tide level (DLLT) plotted with respect to the mean lower low water mark (MLLW)

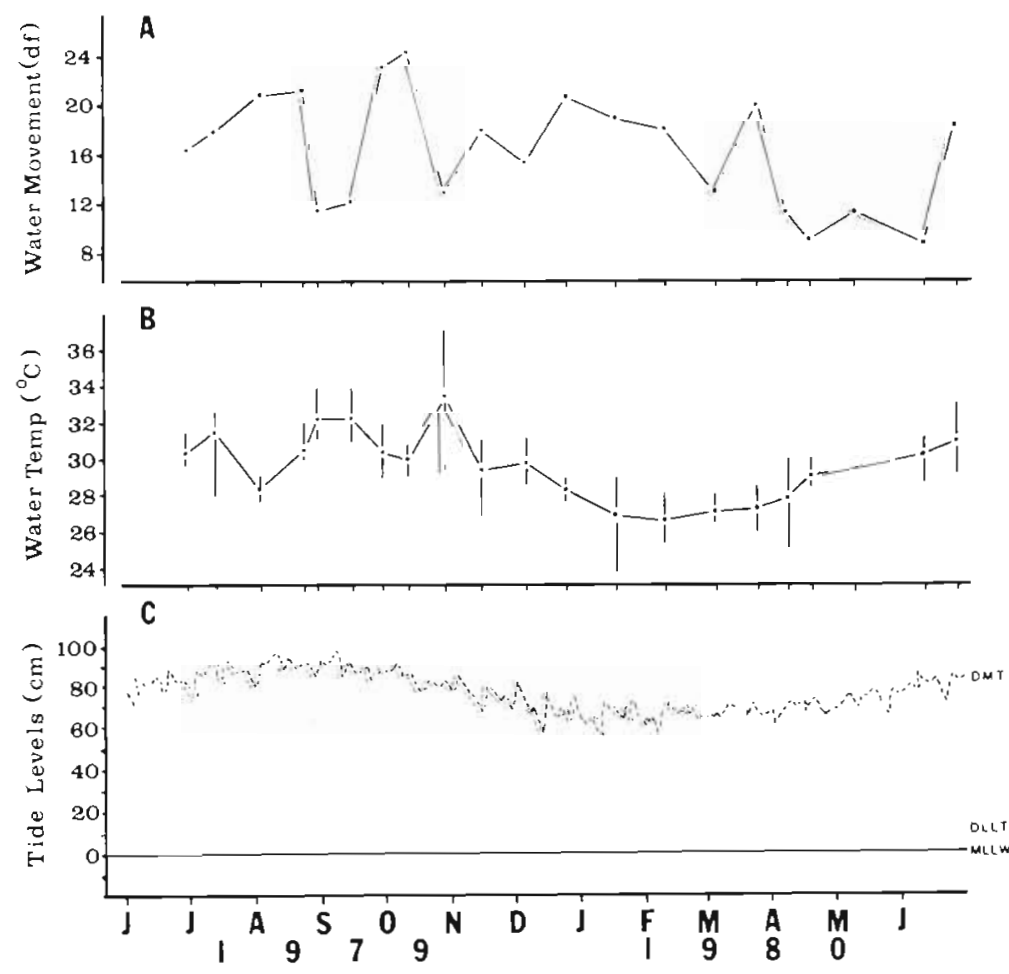


Table 2. Mean percentage cover of the dominant algal species (variables). $\mathrm{S}=$ shoreward quadrats, $\mathrm{M}=$ middle quadrats, $\mathrm{D}=$ quadrats close to the drop off

\begin{tabular}{|c|c|c|c|c|c|c|c|c|c|c|}
\hline \multirow[t]{2}{*}{ Date } & & \multirow{2}{*}{$\begin{array}{c}\text { Case } \\
\text { no. }\end{array}$} & \multicolumn{8}{|c|}{ Variables } \\
\hline & & & $\begin{array}{c}\text { Amphiroa } \\
\text { fragi- } \\
\text { lissima }\end{array}$ & $\begin{array}{l}\text { Caulerpa } \\
\text { sertula- } \\
\text { rioides }\end{array}$ & $\begin{array}{l}\text { Dictyota } \\
\text { sp. }\end{array}$ & $\begin{array}{l}\text { Halsmeda } \\
\text { opuntia }\end{array}$ & $\begin{array}{c}\text { Lobophora } \\
\text { variegata }\end{array}$ & $\begin{array}{l}\text { Sargassum } \\
\text { spp. }\end{array}$ & $\begin{array}{l}\text { Wet- } \\
\text { month } \\
\text { algae }\end{array}$ & $\begin{array}{l}\text { Dry- } \\
\text { month } \\
\text { algae }\end{array}$ \\
\hline \multirow[t]{2}{*}{ Jun 29,1979} & $\mathrm{M}$ & 1 & 1.8 & 0.6 & 0.3 & 0.7 & 0.3 & 39.1 & 0.1 & 0.1 \\
\hline & $\mathrm{D}$ & 2 & 0.2 & 0.6 & 0.0 & 0.2 & 0.0 & 78.9 & 0.0 & 0.0 \\
\hline \multirow[t]{3}{*}{ Aug 24,1979} & S & 3 & 1.8 & 0.0 & 0.0 & 0.1 & 0.4 & 34.8 & 0.0 & 0.0 \\
\hline & M & 4 & 5.6 & 0.0 & 0.0 & 0.0 & 3.4 & 51.6 & 1.2 & 0.0 \\
\hline & $\mathrm{D}$ & 5 & 0.8 & 0.0 & 0.0 & 0.4 & 2.7 & 50.5 & 0.0 & 0.0 \\
\hline \multirow[t]{3}{*}{ Oct 27,1979} & $\mathrm{~S}$ & 6 & 1.7 & 0.1 & 0.0 & 0.0 & 0.0 & 14.7 & 0.1 & 0.0 \\
\hline & $M$ & 7 & 8.4 & 0.0 & 0.0 & 0.0 & 0.0 & 74.4 & 0.1 & 0.0 \\
\hline & $\mathrm{D}$ & 8 & 1.2 & 0.0 & 0.0 & 0.4 & 0.5 & 93.6 & 0.4 & 0.0 \\
\hline \multirow[t]{3}{*}{ Dec 2,1979} & $\mathrm{~S}$ & 9 & 1.4 & 1.0 & 0.0 & 0.4 & 0.4 & 6.4 & 0.0 & 0.2 \\
\hline & M & 10 & 4.9 & 0.3 & 0.8 & 0.6 & 0.6 & 11.0 & 2.1 & 0.0 \\
\hline & D & 11 & 0.7 & 0.4 & 0.0 & 0.0 & 0.0 & 23.8 & 0.0 & 0.0 \\
\hline \multirow[t]{3}{*}{ Feb 8,1980} & S & 12 & 1.8 & 0.0 & 1.6 & 0.5 & 0.0 & 4.8 & 0.0 & 0.3 \\
\hline & M & 13 & 1.6 & 0.0 & 0.0 & 0.0 & 0.8 & 94 & 0.0 & 0.2 \\
\hline & $\mathrm{D}$ & 14 & 10.5 & 0.8 & 0.0 & 0.0 & 0.0 & 17.3 & 0.0 & 0.2 \\
\hline \multirow[t]{3}{*}{ Apr 9,1980} & S & 15 & 0.8 & 3.4 & 0.0 & 0.0 & 0.0 & 4.2 & 0.0 & 0.1 \\
\hline & $M$ & 16 & 4.4 & 1.8 & 1.6 & 0.2 & 0.0 & 21.2 & 0.0 & 1.4 \\
\hline & D & 17 & 8.1 & 0.8 & 0.5 & 1.6 & 0.0 & 21.2 & 0.0 & 0.4 \\
\hline \multirow[t]{3}{*}{ Jun 28,1980} & $\mathrm{~S}$ & 18 & 1.6 & 0.0 & 0.0 & 1.4 & 0.0 & 23.2 & 0.2 & 0.0 \\
\hline & M & 19 & 1.3 & 2.0 & 0.0 & 1.0 & 0.0 & 36.8 & 0.1 & 0.0 \\
\hline & $\mathrm{D}$ & 20 & 5.1 & 5.6 & 1.0 & 2.6 & 0.0 & 39.6 & 0.1 & 0.3 \\
\hline
\end{tabular}

Further analysis of the vegetation data, with Sargassum removed, indicates that $96 \%$ of the variation can be explained by the first component axis alone. The resulting scatter plot (not shown) is basically the same as that in Fig. 4, with the data points divided into 2 clusters corresponding respectively to cases with high and low algal covers.

Table 3. Correlations between the Principal Component scores and the original variables of the vegetation data. In parentheses are the percentages of the variance accounted for by each variable in the particular component axis

\begin{tabular}{|c|c|c|c|}
\hline \multirow[t]{2}{*}{ Variables } & \multicolumn{3}{|c|}{ Component axes } \\
\hline & PCA 1 & PCA 2 & \\
\hline Amphiroa fragilissima & $0.9976^{\cdots} \cdot(16)$ & 0.0148 & (3) \\
\hline Caulerpa sertularioides & $0.8807^{\cdots} \cdot(9)$ & 0.1316 & (2) \\
\hline Dictyota sp. & $0.9889^{\cdots}(16)$ & 0.0693 & (1) \\
\hline Halimeda opuntia & $0.9835 \cdots(13)$ & -0.0593 & $(<1)$ \\
\hline Lobophora variegata & $0.9411^{\cdots(13)}$ & -0.0941 & (1) \\
\hline Sargassum spp. & $0.0929 \quad(<1)$ & $-0.9914 \cdots$ & $(96)$ \\
\hline Wet-month algae & $0.9935 \cdots(16)$ & -0.0090 & $(<1)$ \\
\hline Dry-month algae & $0.9963 \cdots(16)$ & 0.0355 & $i<1)$ \\
\hline$\%$ Variance & 85.53 & 10.00 & \\
\hline$\cdots p \leqslant 0.01$ & & & \\
\hline
\end{tabular}

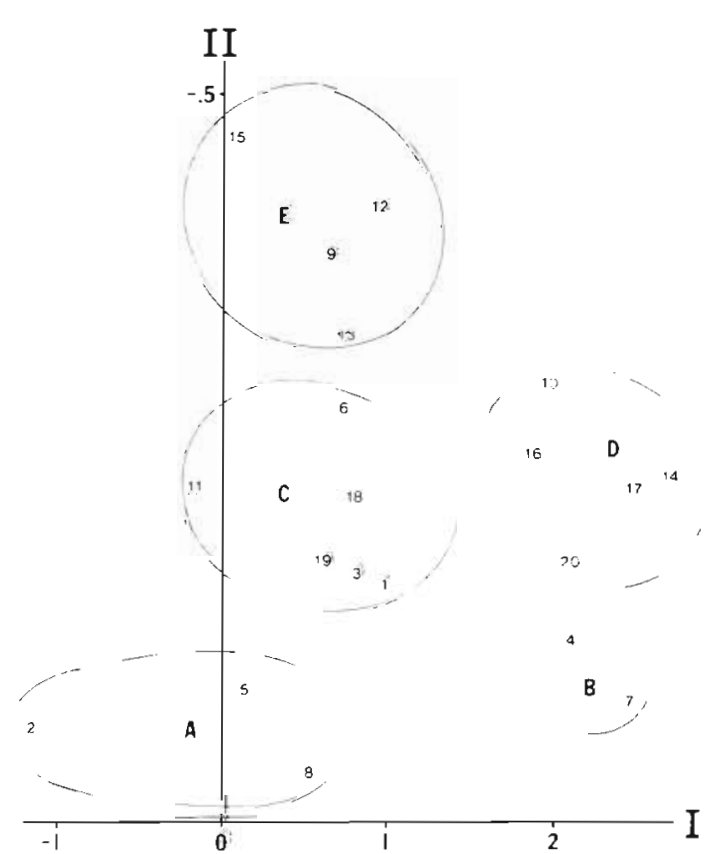

Fig. 4. Scatter diagram of plots on the first 2 PCA axes of the vegetation data $(95 \%$ of the variance explained). Numbers correspond to the cases in Table 2. See text for explanation of Clusters $A$ to $E$ 
Table 4. Correlation between the Principal Component scores and the original variables of the regular environmental data. In parentheses are the percentages of the variance accounted for by each variable in the particular component axis

\begin{tabular}{|c|c|c|c|}
\hline \multirow{3}{*}{ Variables } & \multicolumn{3}{|c|}{ Component axes } \\
\hline & ENV 1 & ENV 2 & ENV 3 \\
\hline & $0.9985 \cdots(96)$ & $-0.0359 \quad(<1)$ & $0.0393(2)$ \\
\hline Max temp. & $-0.0906 \quad(<1)$ & $0.9050 \cdots(32)$ & $0.3447 \quad(19)$ \\
\hline Min temp. & $-0.0287 \quad(<1)$ & $0.8728 \cdots(12)$ & $0.0555(<1)$ \\
\hline Mean temp. & $-0.0950 \quad(<1)$ & $0.9523^{*} \cdot(21)$ & $0.2887(8)$ \\
\hline Salinity & $-0.5175^{\circ} \quad(2)$ & $-0.4364 \quad(5)$ & 0.4124 \\
\hline Daylength & $0.1960 \quad(<1)$ & $0.3936 \quad(2)$ & $-0.5252 \cdot(14)$ \\
\hline Sol. react phosphorus & $0.3282 \quad(<1)$ & $0.8493^{\cdots}(<1)$ & $0.3699(<1)$ \\
\hline Mean lowest tide & $0.2827 \quad(<1)$ & $0.6671 \cdots(14)$ & $-0.5525^{\circ}(39)$ \\
\hline Mean tide & $0.3330 \quad(<1)$ & $0.8255^{\cdots}(13)$ & $-0.0308 \quad(<1)$ \\
\hline$\%$ Variance & 69.68 & 19.45 & 4.79 \\
\hline$\cdot 0.01<p \leqslant 0.05 ; \cdots p \leqslant 0.01$ & & & \\
\hline
\end{tabular}

Results of PCA of the regular environmental data matrix (Table 4) indicate the first axis (ENV 1) to be almost a pure expression of the variation in water movement (Df). The second axis (ENV 2) is a description of changes in temperature and tide levels. Daylength and other aspects of changes in mean lowest tide account for the variation in the third axis (ENV 3 ). However, the percentage of variance attributable to the third axis is too small to be of significance. The first 2 axes alone account for $89 \%$ of the total variation in the environmental data.

PCA of the antecedent environmental data (Table 5) also indicates the first axis (ANT 1) to be accounted for mainly by variation in water movement. However the second axis (ANT 2) describes primarily the changes in minimum temperature and the mean lowest tide. The 2 axes account for $88 \%$ of the total variation. The third axis (ANT 3), which describes the variations in max- imum temperature, mean temperature and salinity, is insignificant.

Canonical Correlation Analysis between the vegetation and the regular environmental component axes (Table 6) reveals a significant correlation between the first pair of canonical variates. Fifty \% of the variance is extracted from the first vegetation variate and of this $97 \%$ is accounted for by PCA 2. Contribution from PCA $1(3 \%)$ is insignificant. From the redundancy value, $25 \%$ of the extracted variance is explained by the environmental variate. As indicated in the interset correlation coefficient, $49 \%$ of the variation in PCA 2 is attributable to the first environmental variate, of which $50 \%$ of the variance of the environmental components has been extracted. This variance is mainly contributed by ENV 2 (77\%). The second pair of canonical variates does not show significant correlation. Although $50 \%$ of the vegetation variance has

Table 5. Correlation between the Principal Component scores and the original variables of the antecedent environmental data. In parentheses are the percentages of the variance accounted for by each variable in the particular component axis

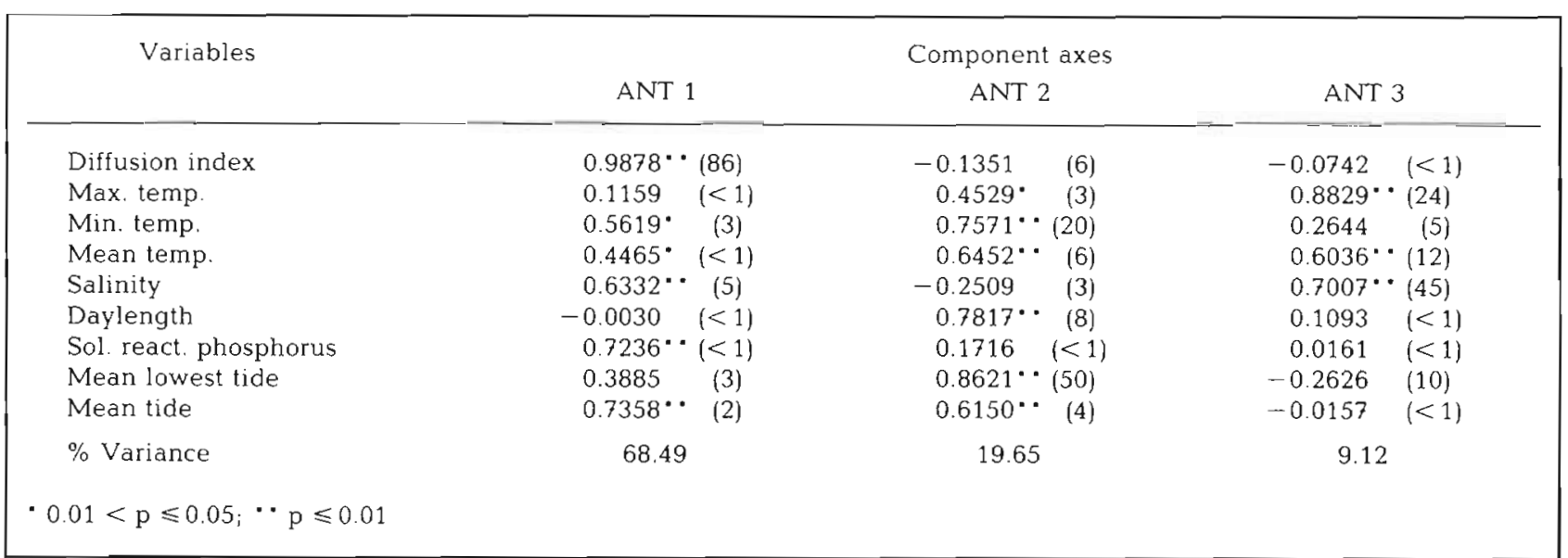


Table 6. Correlations between Canonical variables and original variables, variance extractec, redundancy, and communality of the Canonical Analysis between the vegetation and regular environmental component axes. in parentheses are the percentages of the variance accounted for by the particular component at a particular Canonical Variate

\begin{tabular}{|c|c|c|c|c|c|c|}
\hline \multirow[t]{2}{*}{ Canonical variates } & \multicolumn{2}{|c|}{ Intraset correlation } & \multirow{2}{*}{$\begin{array}{l}\text { Intraset } \\
\text { commu- } \\
\text { nalities }\end{array}$} & \multicolumn{2}{|c|}{ Interset correlation } & \multirow{2}{*}{$\begin{array}{l}\text { Interset } \\
\text { commu- } \\
\text { nalities }\end{array}$} \\
\hline & 1 & 2 & & 1 & 2 & \\
\hline \multicolumn{7}{|l|}{ Vegetation components } \\
\hline PCA 1 & $-0.1657(3)$ & $-0.9862(97)$ & 1.000 & $-0.1180(1)$ & $-0.0921(1)$ & 0.0224 \\
\hline PCA 2 & $-0.9862(97)$ & $-0.1657(3)$ & 1.000 & $-0.7020(49)$ & $-0.0155(<1)$ & 0.4930 \\
\hline Extracted variance & 0.5 & 0.5 & 1.000 & 0.2534 & 0.0044 & 0.2578 \\
\hline Redundancy & 0.2534 & 0.0044 & 0.2578 & 0.2534 & 0.0044 & 0.2578 \\
\hline \multicolumn{7}{|c|}{ Environmental components } \\
\hline ENV 1 & $0.4745(23)$ & $0.8803(77)$ & 1.000 & & & \\
\hline ENV 2 & $0.8803(77)$ & $-0.4745(23)$ & 1.000 & & & \\
\hline Extracted variance & 0.5 & 0.5 & 1.000 & & & \\
\hline Redundancy & 0.2534 & 0.0044 & 0.2578 & & & \\
\hline $\begin{array}{l}\text { Canonical correlation } \\
\text { coefficient }(r)\end{array}$ & $0.7118^{\circ}$ & 0.0933 & & & & \\
\hline Largest root $\left(\mathrm{r}^{2}\right)$ & 0.5067 & 0.0087 & & & & \\
\hline$\cdot p<0.05$ & & & & & & \\
\hline
\end{tabular}

been extracted, less than $1 \%$ (redundancy value) of this is explained by the environmental variate. The interset correlation coefficients of ENV 1 and ENV 2 are not shown in Table 6 . This is mainly because the present analysis is directed, i.e. it is concerned with the influence of environmental parameters on algal cover, and not vice versa. Hence, these correlation coefficients of ENV 1 and ENV 2 have no ecological significance (Gittins 1979).

The relation between the first pair of canonical variates can be summarized in Fig. 5. All the cases can roughly be grouped into 2 clusters. Cluster I is composed of cases taken in the latter half of the year (Jun to Oct) when the Sargassum cover was greater and the water temperature and tide levels were high. Cluster II is composed of cases from December to April, when the Sargassum cover was less, and both temperature and tide levels were also low.

Canonical Correlation Analysis between the vegetation and antecedent environmental component axes (Table 7) also shows a significant correlation in the first canonical axis. Vegetation variate of the first canonical axis is again primarily accounted for by PCA $2(92 \%)$. However, both ANT $1(57 \%)$ and ANT $2(43 \%)$ are important in explaining the variation $(27 \%)$ of this vegetation variate. The second vegetation variate is contributed largely by PCA 1 , but less than $1 \%$ (redundancy value) of its extracted variance $(50 \%)$ is explained by the environmental variate.

Fig. 6 summarizes the relation between the first pair of vegetation and antecedent environmental variates.
The basic pattern of data point scattering is the same as that in Fig. 5. Cluster I includes cases taken in the latter half of the year when strong water movement was experienced with higher mean lowest tide level and higher minimum temperature, these being of importance as antecedent environmental factors to higher Sargassum spp. cover. Cluster II includes cases

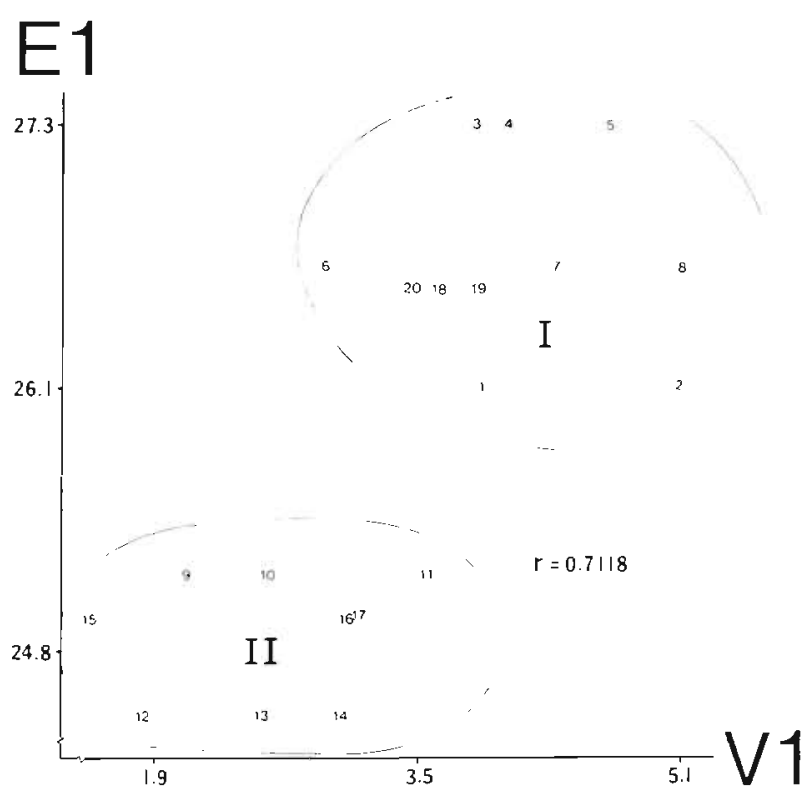

Fig. 5. Scatter diagram of plots on the first canomical axis of the environmental data (E1) and the first canonical axis of the vegetation data (V1). Numbers indicate cases in the data matrix. See text for explanation of the clusters 
Table 7. Correlations between Canonical variables and original variables, variance extracted, redundancy, and communality of the Canonical Analysis between the vegetation and antecedent environmental component axes. In parentheses are the percentages of the variance accounted for by the particular component at the particular Canonical Variate

\begin{tabular}{|c|c|c|c|c|c|c|}
\hline \multirow[t]{2}{*}{ Canonical variates } & \multicolumn{2}{|c|}{ Intraset correlation } & \multirow{2}{*}{$\begin{array}{l}\text { Intraset } \\
\text { commu- } \\
\text { nalities }\end{array}$} & \multicolumn{2}{|c|}{ Interset correlation } & \multirow{2}{*}{$\begin{array}{l}\text { Interset } \\
\text { commu- } \\
\text { nalities }\end{array}$} \\
\hline & 1 & 2 & & 1 & 2 & \\
\hline \multicolumn{7}{|l|}{ Vegetation components } \\
\hline PCA 1 & $-0.2755(8)$ & $-0.9613(92)$ & 1.000 & $-0.2022(4)$ & $-0.0306(<1)$ & 0.0418 \\
\hline PCA 2 & $-0.9613(92)$ & $-0.2755(8)$ & 1.000 & $-0.7049(50)$ & $0.0088 i<1)$ & 0.4970 \\
\hline Extracted variance & 0.5 & 0.5 & 1.000 & 0.2689 & 0.0005 & 0.2694 \\
\hline Redundancy & 0.2688 & 0.0005 & 0.2693 & 0.2688 & 0.0005 & 0.2693 \\
\hline \multicolumn{7}{|c|}{ Environmental components } \\
\hline ANT 1 & $0.7559(57)$ & $0.6546(43)$ & 1.000 & & & \\
\hline ANT 2 & $-0.6546(43)$ & $0.7559(57)$ & 1.000 & & & \\
\hline Extracted variance & 0.5 & 0.5 & 1.000 & & & \\
\hline Redundancy & 0.2688 & 0.0005 & 0.2693 & & & \\
\hline $\begin{array}{l}\text { Canonical correlation } \\
\text { coefficient (r) }\end{array}$ & $0.7333^{\circ}$ & 0.0319 & & & & \\
\hline Largest root $\left(\mathrm{r}^{2}\right)$ & 0.5377 & 0.0010 & & & & \\
\hline$\cdot p<0.05$ & & & & & & \\
\hline
\end{tabular}

in December. This is the transition period when tide levels and water temperature were becoming low and the Sargassum plants starting to die back. Cluster III includes cases in February and April, with lowest temperature and lowest low tide level preceeding the low cover of Sargassum.

Attempts to correlate all the other associated mac-

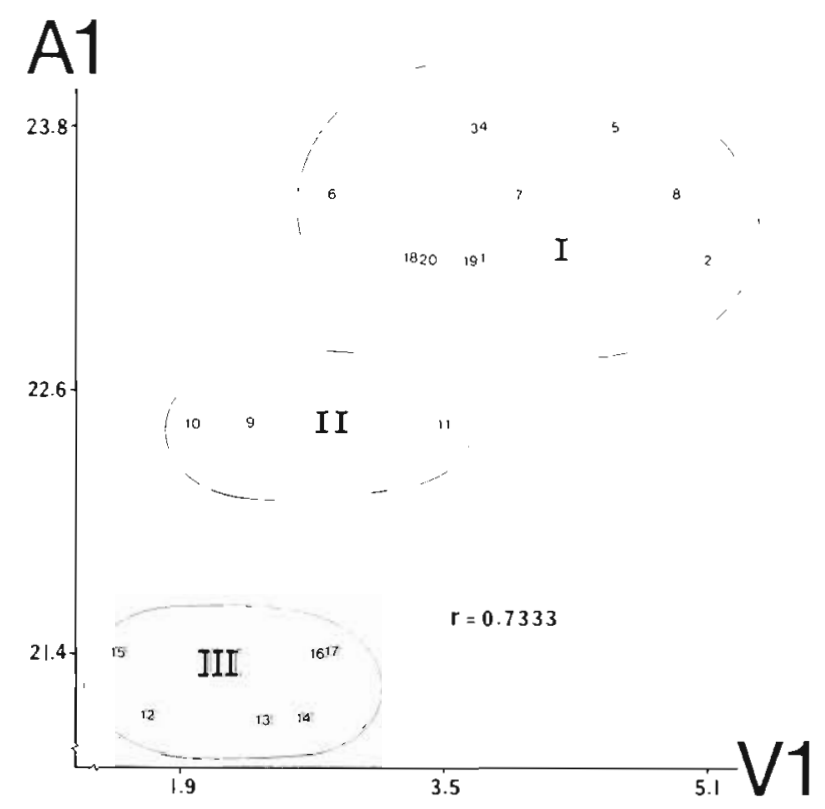

Fig. 6. Scatter diagram of plots on the first canonical axis of the antecedent environmental data (A1) and the first canonical axis of the vegetation data (V1). Numbers indicate cases in the data matrix. See text for explanation of the clusters robenthic algae, when treated together without Sargassum, with both sets of environmental data are unsuccessful. No significant correlation can be extracted between the variations in the percentage cover of these algae and those of the environmental parameters.

\section{DISCUSSION}

As would be expected from a gradually sloping substratum, the zonation pattern of the Sargassum spp. in Calatagan, Batangas was not as discrete as that observed by Tsuda (1972) between S. polycystum J. $\mathrm{Ag}$. and $S$ cristaefolium C. Ag. in Guam. It was more similar to the pattern observed by Yoshida et al. (1963) in North Kyushu, Japan, where there was some overlap in the distribution of the different Sargassum species. Zonation is believed to be influenced by biological interactions along a gradient of environmental parameters (Chapman 1973). Constant submergence and strong surf action are probably critical to those species of Sargassum found only on the reef edge. Although the amplitude of tropical tides is small, the gradual slope of the reef flat along the shore at Balibago, Calatagan enables a large expanse to be exposed for considerable periods at extreme low tide. This may have contributed to the zonation of the 2 dominant Sargassum species in the area. However, no zonation pattern was observed among the associated macrobenthic algae. Biological interaction among the different species is unclear. 
Although Sargassum was far more dominant than the rest of the algal species, results of PCA indicate that the variation in the community structure was significantly contributed to by the less dominant species taken together. This is evident from the further analysis of the vegetation data with Sargassum removed. Indeed, a Sargassum community would appear to be monotonously uniform except for its seasonal changes in algal cover contributed by the growth and wane of Sargassum plants. Growth in various Sargassum species follows a seasonal pattern (De Wreede 1976, McCourt 1984, Ang 1985). Thallus lengths of species examined in this study were positively correlated with their cover $(r=0.7731, p<0.05)$. This suggests that the seasonal variation in their percentage cover was a direct consequence of their seasonal growth. Other associated species, however, did not appear to exhibit such a pattern. These species may show seasonality in their occurrence and growth, but these were not reflected in the changes in their cover. Variations contributed by these other species, when taken individually, are easily masked by the dominance of Sargassum such that their contributions become less obvious to the overall structure of the community.

The variations contributed by the less dominant species, however, can not be explained by changes in the environmental parameters. Canonical Correlation Analyses may not indicate the direct causative effect of environmental parameters on the algal cover. The information generated, however, can well serve as a basis for inference. Analysis using the regular environmental data may indicate those parameters which are of more immediate influence on algal cover.

The correlation coefficients of the first canonical axis in both analyses are rather close. Both have extracted temperature and tide levels as significantly correlated with primarily Sargassum cover. While temperature may have immediate significance to the physiology of the plants, high water level can enhance light penetration by minimizing the shading effect among the erect thalli. Stronger water movement experienced by the algae during the typhoon months of June to November may have contributed to the aeration and nutrient regeneration within the Sargassum community. This provides a better environment for the growth of Sargassum as well as possibly that of other algae. Antecedent events like minimum temperature and lowest tide level may have far reaching effect on algal growth. Lowest temperature has been shown to influence the survival of Sargassum embryos (De Wreede 1978). Low tide started to occur during daytime in October and tide level became lowest in December to February. This exposed Sargassum plants to excessive dessication. Most of the plants lost their erect thalli during this period to start subsequently a new cycle of growth.
This explains the low percentage cover of Sargassum in February and April.

Most of the associated algae were present in February at a time when Sargassum cover was lowest and least in August and October when Sargassum cover was highest. It is possible that Sargassum may have exerted a canopy effect on the recruitment and growth of some of these species. A similar effect has been observed by Dayton (1975) for Laminaria and Agarum species on the growth of red algal turf beneath them, and on suppressing the recruitment and growth of Alaria fistulosa Post et Rupr. In the present study, those species found only during the latter half of the year may prefer a shaded light condition under the canopy of maximum Sargassum growth, but this has to be verified experimentally.

The time period used in setting the interval between the onset of the environmental events and the manifestation of the effect in algal cover was 2 to $3 \mathrm{wk}$. This corresponds to approximately half of a lunar cycle. Other environmental variables may have an antecedent effect shorter than this period. On the other hand, although it may still be possible to obtain significant correlation between events occurring at intervals greater than $3 \mathrm{wk}$, such correlation may be more difficult to justify in a biological sense.

Acknowledgements. Part of this work is based on the Master's thesis submitted to the College of Arts and Sciences, University of the Philippines (U.P.). Partial financial support was provided by the Filipinas Foundation Inc to Dr. G. C. Trono Jr. through the U.P. Marine Sciences Center and a thesis grant from the U.P. Natural Science Research Center. I thank Drs. G. Trono Jr. and E. Gomez of U.P., Drs. R. De Wreede, G. Bradfield and J. Maze of the University of British Columbia (U.B.C.) and 3 anonymous reviewers for comments, discussions and suggestions. Dr. J. Tablante helped throughout the field. Computer time at U.B.C. was gratefully paid for by a University grant to Dr. R. De Wreede.

\section{LITERATURE CITED}

Aart, P. J. M., Smeenk-Enserink, N. (1975). Correlation between distributions of hunting spiders (Lycosidae, Ctenidae) and environmental characteristics in a dune area. Neth. J. Zool. 25: 1-25

Ang, P. Jr. (1982). Studies on the taxonomy of the genus Sargassum (Phaeophyta) and the phenology and some aspects of the ecology of $S$. siliquosum $\mathrm{J}$. Ag and $S$. paniculatum J. Ag. in Balibago, Calatagan, Batangas. M. Sc. thesis, University of the Philippines, Diliman, Quezon City

Ang, P. Jr (1985). Phenology of Sargassum siliquosum J. Ag. and $S$ paniculatum J. Ag. in the reef flat of Balibago, Calatagan, Philippines. Proc. Coral Reef Symp. 5. In press

Chapman, A. R. O. (1973). A critique of prevailing attitudes towards the control of seaweed zonation on the seashore. Botanica Mar 16: 80-82

Cordero, P. A. Jr (1978). Phycological observation VI. Man- 
grove associated algae from Aklan, Philippines. Kalikasan, Philipp. J. Biol. 7 : 275-296

Cordero, P. A. Jr. (1980). Phycological observation VII. On the occurrence and phyco-geographical distribution of Sargassum duplicatum and Halicoryne wrightii in the Philippines. Publs Seto mar. biol. Lab. 25: 27-38

Dayton, P. K. (1975). Experimental studies on algal canopy interactions in a sea otter-dominated kelp community at Amchitka Island. Alaska Fish. Bull. 73: 230-237

De Wreede, R. E. (1976). The phenology of the three species of Sargassum (Sargassaceae, Phaeophyta) in Hawaii. Phycologia 15: 175-183

De Wreede, R. E. (1978). Growth in varying culture conditions of embryos of three Hawaiian species of Sargassum (Phaeophyta, Sargassaceae). Phycologia 17: 23-31

Doty, M. S. (1971a). Measurements of water movement in reference to benthic algal growth. Botanica Mar. 14: 32-35

Doty, M. S. (1971b). Antecedent event influence on benthic marine algal standing crops in Hawaii. J. exp. mar Biol. Ecol. 6: 161-166

Fox, D. J., Guire, K. E. (1976). Documentation for MIDAS. 3rd ed. Statistical Research Laboratory, University of Michigan, Michigan

Gittins, R. (1979). Ecological applications of canonical analysis. In: Orloci, L., Rao, C. R., Stiteler, W. M. (ed.) Multivarj- ate methods in ecological work. Stat. Ecol. Ser. 7 Int. Cooperative Publ. Ho., Fairland, Maryland, p. 309-535

Jeffers, J. N. R. (1978). An introduction to system analysis, with ecological implications. Univ. Park, Baltimore

Legendre, L., Legendre, P. (1983). Numerical ecology. Elsevier, New York

McCourt, R. M. (1984). Seasonal patterns of abundance, distributions and phenology in relation to growth strategies of three Sargassum species. J. exp. Mar. Biol. Ecol. 74: $141-156$

Saito, Y., Atobe, S. (1970). Phytosociological study of intertidal marine algae. I. Usujiri Benten-Jima, Hokkaido. Bull. Fac. Fish. Hokkaido Univ. 21 (2): 37-69

Saraya, A. (1976). Taxonomy and ecology of marine benthic algae of Santiago Island and adjacent areas. Ph. D. thesis, University of the Philippines, Diliman, Quezon City

Strickland, J. D. H., Parsons, T R. (1972). A practical handbook of seawater analysis. Bull. Fish. Res. Bd Can. 167

Tsuda, R. T (1972). Morphological, zonational, and seasonal studies of two species of Sargassum on the reefs of Guam. Proc. Int'l Seaweed Symp. 7: 40:44

Yoshida, T., Sawada, T., Higaki, M. (1963). Sargassum vegetation growing in the sea around Tsuyazaki, North Kyushu, Japan. Pacif. Sci. 17: 135-144

This paper was submitted to the editor ${ }_{i}$ it was accepted for printing on September 16, 1985 